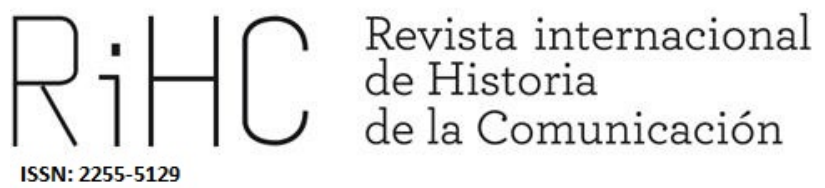

\title{
LA PRENSA GALLEGA DE BUENOS AIRES Y SU APOYO AL FRANQUISMO: ESTRATEGIAS PROPAGANDÍSTICAS Y ACTIVISMO POLÍTICO
}

Galician newspapers of Buenos Aires and their support for Francoism: propaganda strategies and political activism

DOI: http://dx.doi.org/10.12795/RiHC.2019.i12.09

Recibido: 05/03/2019

Aceptado: 03/04/2019

Publicado:15/06/2019

Nadia Andrea De Cristóforis

Universidad de Buenos Aires -

Universidad Nacional de Luján -

Consejo Nacional de Investigaciones Científicas y Técnicas (Argentina)

ndecristoforis@yahoo.com.ar

ORCID (iD) 0000-0003-4091-8716

Como citar este artículo: DE CRISTÓFORIS, Nadia Andrea (2019): “La prensa gallega de Buenos Aires y su apoyo al Franquismo: estrategias propagandísticas y activismo político”, en Revista Internacional de Historia de la Comunicación (12), pp. 178-200. 
Resumen: La Guerra Civil española produjo significativas repercusiones dentro de la comunidad gallega instalada en la ciudad de Buenos Aires, generando debates y tensiones dentro de sus instituciones y periódicos. En este artículo nos concentraremos en dos publicaciones creadas por los oriundos del noroeste hispánico en la ciudad porteña: Correo de Galicia, surgida el 22 de marzo de 1908, y Fe Gallega, originada el 1o de noviembre de 1936. Ambas se convirtieron en importantes órganos de apoyo y propaganda del bando nacional. Analizaremos sus características, contenidos y las formas de activismo político que promovieron, en su objetivo de contribuir a la consolidación del franquismo de uno y otro lado del océano Atlántico.

Palabras clave: Comunidad gallega, Buenos Aires, Correo de Galicia, Fe Gallega, franquismo.

\begin{abstract}
The Spanish Civil War produced significant implications within the Galician community in the city of Buenos Aires. It generated debates and tensions within its institutions and newspapers. In this article we will concentrate on two publications created by Galicians in Buenos Aires: Correo de Galicia, born on March 22, 1908, and Fe Gallega, originated on November 1, 1936. Both became important organs for support and propaganda of the national side. We will discuss their features, contents and the forms of political activism promoted in order to contribute to the consolidation of Francoism on both sides of the Atlantic Ocean.
\end{abstract}

Keywords: Galician community, Buenos Aires, Correo de Galicia, Fe Gallega, Francoism.

\title{
Introducción: objetivos, metodología y fuentes
}

La Guerra Civil española generó fuertes repercusiones dentro de la comunidad hispánica instalada en la ciudad de Buenos Aires, por tratarse de un colectivo inmigratorio de larga data y con una importante dimensión numérica para la década de 1930. Según el Censo de Buenos Aires de 1936, en este año el número de peninsulares instalados en la capital argentina llegaba a las 324.650 personas de ambos sexos (Cuarto Censo General..., 1936: 16), de las cuales entre un 45 y 50\% eran gallegos (Moya, 2004: 28). Estos últimos constituían el principal grupo inmigratorio español en la ciudad porteña, desde un punto de vista regional.

La contienda impactó dentro de esta comunidad del noroeste hispánico de distintos modos y con efectos variables, tanto a nivel familiar y/o personal como dentro del amplio tejido institucional generado por los inmigrantes, suscitando debates, tensiones y alineamientos a favor de uno y otro bando. En este artículo nos concentraremos principalmente en dos publicaciones creadas por los gallegos en Buenos Aires: una que preexistía al levantamiento y databa del 22 de marzo de 1908 (Correo de Galicia) y otra que tuvo su origen el 1 o de noviembre de 1936, al poco tiempo de iniciada la Guerra 
Civil (Fe Gallega). Ambas se convirtieron en importantes órganos de apoyo y propaganda del bando nacional en la capital argentina.

Correo de Galicia fue fundado y dirigido por un inmigrante oriundo de A Coruña, José Ramón Lence. Constaba de unas dieciséis a veinte páginas y se publicó semanalmente (con una tirada de entre cuatro y cinco mil ejemplares) y de manera ininterrumpida hasta 1946, año en que cambió su nombre por Nuevo Correo, designación que fue mantenida hasta el fallecimiento de su director en 1951. Se financiaba gracias a las suscripciones y los avisos publicitarios que aparecían en sus páginas, y tuvo sus domicilios en la Avenida de Mayo 1370 y luego en la Avenida Rivadavia 782 de la ciudad de Buenos Aires.

Fe Gallega surgió en cambio como órgano de la Acción Gallega de Cruzados de Santiago, una institución fundada en Buenos Aires el 25 de julio de 1936 y que a partir de julio de 1938 cambió su nombre por Cruzados Gallegos de Santiago Apóstol. El último número que se conserva de Fe Gallega data de abril de 1942, momento en el que la misma había alcanzado sus treinta y nueve números. Tendió a presentar una frecuencia mensual y poseía por lo general unas cuatro páginas (siendo algunos de sus números más extensos). Su distribución era gratuita. La impresión era financiada por promotores o "padrinos" (alrededor de una veintena de miembros de la comunidad que aportaban una cuota mensual de $\$ 5$ pesos moneda/nacional cada uno ${ }^{1}$ ) y por la venta de espacios publicitarios. Los domicilios de Fe Gallega fueron cambiando en la medida en que la institución de la cual era vocero mudó su sede social dentro de la Capital Federal: primero se localizó en Florida 621, luego en Bernardo de Irigoyen 483 y finalmente en Victoria 676.

A lo largo de nuestro trabajo analizaremos las características, los contenidos y las formas de activismo político que promovieron ambas publicaciones, en su objetivo de contribuir a la consolidación del franquismo de uno y otro lado del océano Atlántico. Para ello, realizamos una lectura intensiva de los números de Correo de Galicia correspondientes a los años de la Guerra Civil española (de julio de 1936 a abril de 1939) y de los números de Fe Gallega desde su aparición en noviembre de 1936 hasta el fin de la contienda. La información obtenida fue contrastada y complementada con la bibliografía existente sobre cuestiones históricas y contextuales afines a nuestro tema de indagación.

\footnotetext{
1 “Fe Gallega”, Fe Gallega, agosto de 1938, año II, no 19, p. 2.
} 


\section{La prensa gallega en Buenos Aires: características e historiografía sobre el tema}

Las migraciones gallegas hacia la ciudad porteña se intensificaron desde fines del siglo XVIII (De Cristóforis, 2009), alcanzando dimensiones masivas entre el último tercio del siglo XIX y principios del XX (Villares y Fernández, 1996: 121-122). Se calcula que hacia 1914 la capital argentina era la urbe con más gallegos del planeta (entre 150.000 y 200.000), superando incluso a las principales ciudades de Galicia, como Vigo o La Coruña (Núñez Seixas, 2007: 28).

Esta temprana e importante presencia gallega en Buenos Aires condicionó la aparición de numerosas y variadas instituciones representativas de la comunidad, como asociaciones (a partir de 1787) o periódicos (desde 1879), que proliferaron en el tránsito del siglo XIX al XX. La prensa comunitaria, escrita tanto en lengua gallega como mayoritariamente en castellano, surgió por dos impulsos básicos (aunque no únicos): por un lado, el interés de jóvenes bachilleres que llegaban al Río de la Plata ávidos de insertarse en el mundo periodístico local, y que lograron fundar por iniciativa personal y/o de la mano de un grupo de colaboradores un gran número de periódicos y revistas de variable frecuencia y duración (Núñez Seixas, 2014: 415); y por otro, la necesidad de las asociaciones gallegas de contar con un órgano de difusión de sus actividades y logros, de cara a la masa de sus afiliados. Si los primeros tipos de publicaciones expresaron con mayor libertad reflexiones de índole política referidas a Galicia, España, y en mucha menor medida, la Argentina; las segundas buscaron principalmente reflejar la vida institucional de la entidad que representaban y la evolución de la jurisdicción gallega (la región en su conjunto, la comarca, el consejo o la parroquia, por ejemplo) en la que se referenciaban.

Lamentablemente, la atención que ha recibido la prensa de la comunidad gallega en la Argentina ha sido bastante limitada hasta el momento. No se dispone de estudios exhaustivos que contemplen las publicaciones de los inmigrantes en su conjunto o en amplios marcos temporales, como los de Neira Vilas (1985) para Cuba o Zubillaga (1996) para Uruguay. Tampoco se cuenta con un análisis en profundidad de algún periódico en particular, a lo largo de toda su trayectoria y considerando sus contextos de producción y recepción, como el que ha realizado Garabedian (2017) en el caso de El Correo Español, órgano hispánico publicado en Buenos Aires.

Una obra que tempranamente incorporó la temática de la prensa y los periodistas gallegos en la Argentina fue la de Vilanova Rodríguez (1966), pero en una indagación de largo aliento más preocupada por develar las biografías de los gallegos y la evolución de sus principales instituciones, que por aprovechar la riqueza historiográfica de los periódicos como punto de partida para la reconstrucción de los procesos históricos. 
Posteriormente y de manera general, el abordaje de la prensa de la comunidad del noroeste hispánico en el país austral tuvo lugar en investigaciones que se concentraron en los procesos migratorios desde Galicia hacia la Argentina y que introdujeron a los periódicos como fuente para analizar diversos aspectos de la inserción de dichos migrantes en la sociedad receptora (Farías Iglesias, 2010; Núñez Seixas, 2001, 2002, entre muchos otros ejemplos).

Como ya sugerimos, los estudios que se abocaron a la prensa gallega de la Argentina como objeto central de análisis son escasos, aunque los trabajos de Vieites Torreiro (1989), Cagiao Vila (2002) y Núñez Seixas (2014) constituirían la excepción a esa tendencia general, así como el capítulo de Molinos (1999) podría ser un ejemplo de aproximación a la prensa comunitaria. En el caso de Vieites Torreiro (1989), planteó un examen comparativo de los dos primeros periódicos gallegos en América (El Eco de Galicia en la Habana y El Gallego de Buenos Aires). Por otra parte, Cagiao Vila (2002) trabajó con un conjunto más amplio de periódicos (El Eco de Galicia, Correo de Galicia, El Heraldo Gallego, El Despertar Gallego y el Boletín de la Biblioteca América de la Universidad de Santiago de Compostela), analizando sus temáticas más recurrentes, entre mediados de la década del veinte y mediados de la del treinta. Núñez Seixas (2014) estudió minuciosa y comparativamente la trayectoria de dos importantes periodistas gallegos en la ciudad porteña: José R. Lence y Fortunato Cruces, así como su labor de cara a los dos periódicos por ellos dirigidos, Correo de Galicia y Nova Galicia respectivamente, en el período anterior a la Guerra Civil española. Resulta de interés señalar que este conjunto de trabajos podría complementarse con otro tipo de indagación (Farías, 2008) que se ha preocupado por una destacada revista local de carácter popular, Caras y Caretas, con el fin de extraer de ella toda la información concerniente a los inmigrantes gallegos en la Argentina, entre 1898 y 1923.

Finalmente, y en relación ya más directa con la Guerra Civil española y sus impactos y/o vinculaciones con los periódicos de la comunidad gallega, disponemos de un trabajo que examinó las reacciones de la prensa del noroeste hispánico frente a la contienda, pero como parte de los posicionamientos más amplios de las instituciones y personalidades destacadas de la comunidad de dicha procedencia frente a la Guerra Civil (Fernández García, 1990). Asimismo, también se ha analizado la participación de los exiliados gallegos en el semanario Galicia (órgano oficial de la Federación de Sociedades Gallegas de Buenos Aires), entre 1936 y 1955 (Fasano, 2014: 225-272). Por lo tanto, y como se puede deducir de lo comentado hasta el momento, resta aún conocer cuáles fueron las repercusiones de la Guerra Civil española sobre la prensa gallega que se alineó con las fuerzas sublevadas y la posterior dictadura franquista. 


\section{La Guerra Civil y el apoyo al bando nacional}

Sabido es que Galicia quedó rápidamente bajo el control de los insurgentes, quienes desplegaron una fuerte represión sobre los focos de resistencia y oposición al alzamiento (Fernández Santander, 2000). Las noticias del inicio y la prolongación de la Guerra Civil llegaron inmediatamente a la comunidad gallega emigrada en Buenos Aires, impactando en la evolución de sus asociaciones y periódicos.

Las entidades del noroeste hispánico se fueron definiendo a favor o en contra de uno y otro bando, como en el caso de la mayor parte de las otras instituciones españolas (Fernández García, 1990; Fernández Santiago, 2001). Estos posicionamientos se produjeron temprana o tardíamente, según el caso, y a menudo involucraron disensos y polémicas dentro de los grupos dirigentes o de asociados, o entre unos y otros. Estas tensiones se vieron incrementadas por la llegada de los exiliados gallegos a partir de 1936, quienes buscaron movilizar a sus congéneres en la Argentina y allende el mar a favor del gobierno republicano (Núñez Seixas, 2012).

La prensa de la comunidad gallega, ya se tratase de los voceros de las asociaciones o de órganos independientes de las mismas, también se hizo eco en mayor o menor medida de la contienda que tenía lugar en España, dando cuenta de un activismo político velado o leve, hasta otro mucho más abierto y comprometido con alguno de los dos bandos. Si bien en este trabajo analizaremos dos exponentes periodísticos que se inclinaron a favor del bando nacional, debemos recordar que también existieron otras importantes publicaciones gallegas que bregaron abiertamente por la defensa de la legalidad republicana, siendo uno de los ejemplos más representativos de ello el ya citado semanario Galicia.

Ahora bien, la movilización social y el compromiso político de las asociaciones o la prensa étnica en apoyo de las fuerzas republicanas o nacionales no se produjeron en el vacío. Si bien encontraron importantes motivaciones en la ideología de quienes lideraban o dirigían esas instituciones y en la masa de sus afiliados o lectores, también estuvieron fuertemente condicionados por otro conjunto de factores, tales como: la política exterior, y específicamente americana, que fueron generando ambos bandos contendientes; los posicionamientos de las principales potencias occidentales (Estados Unidos, Francia, Gran Bretaña, Alemania, Italia) a lo largo del desarrollo de la Guerra Civil española; la política que la Argentina adoptó frente a dicha contienda y de cara a la comunidad peninsular instalada en dicho país; la militancia católica desplegada en España o en los países americanos, entre otros. A los fines de nuestro análisis, conviene tener presente que la diplomacia franquista en el Continente Americano buscó atender fundamentalmente dos cuestiones: por un lado, la labor propagandística y diplomática, en virtud de lo cual se apoyó en el accionar personal de agentes oficiosos u oradores 
enviados allende el océano, y por otro, la unión y comunicación de las naciones americanas con la España Nacional, objetivo que se trató de lograr a través del reforzamiento de Falange Exterior, lo que terminó generando tensiones con el servicio diplomático, especialmente dentro de la Argentina (Moreno Cantano, 2008: 558; Pardo Sanz, 1992: 215-216).

En el caso de dicho país sudamericano, la propaganda franquista y el apoyo al movimiento sublevado se canalizó a través de distintos medios (como emisiones radiales, ceremonias de carácter festivo-político-religioso o "misiones culturales" de figuras destacadas del nuevo régimen -una en septiembre de 1937 y otra desde diciembre de este año hasta febrero de 1938-), entre los que destacaron los escritos. En relación con estos últimos, deberíamos tener presente el papel que cumplieron los periódicos locales de gran tirada (como La Nación y La Prensa), los órganos católiconacionalistas (el periódico El pueblo y la revista Criterio), algunos medios escritos nacionalistas (entre otros, La Fronda, Bandera Argentina, Crisol y Clarinada), los periódicos de la comunidad española, o las publicaciones de la Oficina de Prensa y Propaganda de la delegación de Burgos en Buenos Aires (Quijada Mauriño, 1991: 209$211 ; 218-225)$. Además, si bien con ambigüedades, los gobiernos argentinos apoyaron en mayor o menor medida al franquismo a partir de 1936 (Moreno Cantano, 2008: 557; Rein, 1995: 32) y la Iglesia Católica se llegó a convertir en un actor central en la defensa del bando sublevado, desde la alta jerarquía hasta los sacerdotes y párrocos locales. Estos últimos realizaron colectas de prendas de vestir y de ornamentos sagrados para el Ejército Nacional y justificaron su accionar desde el púlpito (Quijada Mauriño, 1991: 180; Rein, 1995: 38; Trifone y Svarzman, 1993: 56).

Ahora bien, en este contexto brevemente descripto, ¿ cómo actuaron Correo de Galicia y Fe Gallega? ¿Qué estrategias específicas y compartidas desarrollaron, de cara a generar entre sus lectores un consenso a favor del bando nacional? Trataremos de analizar estas cuestiones en los apartados que siguen.

\subsection{Correo de Galicia: sus definiciones en tiempos de la Guerra Civil}

En sus Memorias de un periodista, Lence (1954: 341) ponía de manifiesto que desde el comienzo de la Guerra Civil el semanario que dirigía se había colocado del lado del bando nacional. Sin embargo, durante los dos primeros meses de la contienda el posicionamiento de Correo de Galicia no fue tan claro ni explícito. Las editoriales de julio y agosto de 1936, firmadas por el emigrado coruñés, se limitaban a poner de manifiesto su desencanto con el republicanismo y su temor a la anarquía o a la imposición de un 
régimen comunista dentro de España. ${ }^{2}$ Incluso, cuando el 30 de julio de 1936 el periódico Acción Española, del pro franquista Centro Acción Española, lo consultó sobre su opinión sobre la Guerra Civil, Lence se abstuvo de tomar partido por el levantamiento, con respuestas evasivas que contenían rodeos y ambigüedades. ${ }^{3}$ Sin embargo, a partir de la formación del Gobierno Largo Caballero el 4 de septiembre de 1936, las expresiones del director de Correo de Galicia a favor de las fuerzas nacionales ya fueron más abiertas y enfáticas (Fernández García, 1990: 129-130). Sin abrazar el ideario religioso de los insurrectos, Lence les brindó desde Buenos Aires un apoyo laico y contrarrevolucionario (Núñez Seixas, 2014: 450) que se fue consolidando a lo largo de la Guerra Civil y le permitió disfrutar del reconocimiento y agasajos de los franquistas una vez finalizada la contienda, como el homenaje que le organizaron en su honor en el Teatro Ambassadeurs, donde se congregaron representantes del nuevo régimen, junto a unos seiscientos invitados. ${ }^{4}$

Ahora bien, ¿̇uáles fueron las estrategias básicas puestas en juego por Correo de Galicia para generar en sus lectores un sentimiento proclive a la causa nacional? En primer lugar, mantener el formato y las secciones y/o apartados que caracterizaban a la publicación desde antes del inicio de la Guerra Civil española (una primera parte general y cuatro secciones, tituladas: "Información de Galicia", "Movimiento colectivo. Centros y Sociedades", "Semana Española" y "Semana Española del Uruguay"), pero nutriéndolos de contenidos cada vez más favorables a las fuerzas nacionales. Ello daba una imagen de aparente continuidad formal con la etapa previa a la contienda, aunque el discurso a favor de los sublevados se introdujera con gran fuerza en el semanario, remitiendo con detalles minuciosos a todas aquellas actividades que involucraban el apoyo y la solidaridad con la causa. Un ejemplo de esto último lo tenemos cuando en la sección "Información de Galicia" se dio a conocer una suscripción a favor del Ejército Nacional llevada a cabo en tierras del noroeste hispánico, que incluyó el nombre y apellido de todos los contribuyentes, así como sus variados tipos de donativos, que en la mayor parte de los casos, consistían en modestos aportes, tales como: una botella de jerez, una libra de chocolate, un kilo de azúcar blanco, un kilo de macarrones, una peseta, una botella de anís, etc., por parte de diferentes personas. ${ }^{5}$

\footnotetext{
2 LENCE, J.R. (26 de julio de 1936): “En plena Guerra Civil. Grandeza y sacrificio", Correo de Galicia, año XXIX, no 1592, p. 2; Idem (2 de agosto de 1936): “iiiEspaña!!!”, Correo de Galicia, año XXIX, no 1593, p. 1; Idem (23 de agosto de 1936): "La intensa preocupación de la Guerra Civil”, Correo de Galicia, año XXIX, no 1596, p. 1.

3 LENCE, J.R. (2 de agosto de 1936): “Acción Española' y ‘Correo de Galicia’ dos cartas”, Correo de Galicia, año XXIX, no 1591, p. 3.

4 "La demostración ofrecida a nuestro Director", Correo de Galicia, 23 de abril de 1939, año XXXII, no 1735, p. 1.

5 “Suscripción patriótica”, Correo de Galicia, 16 de enero de 1938, año XXX, no 1669, pp. 7-8.
} 


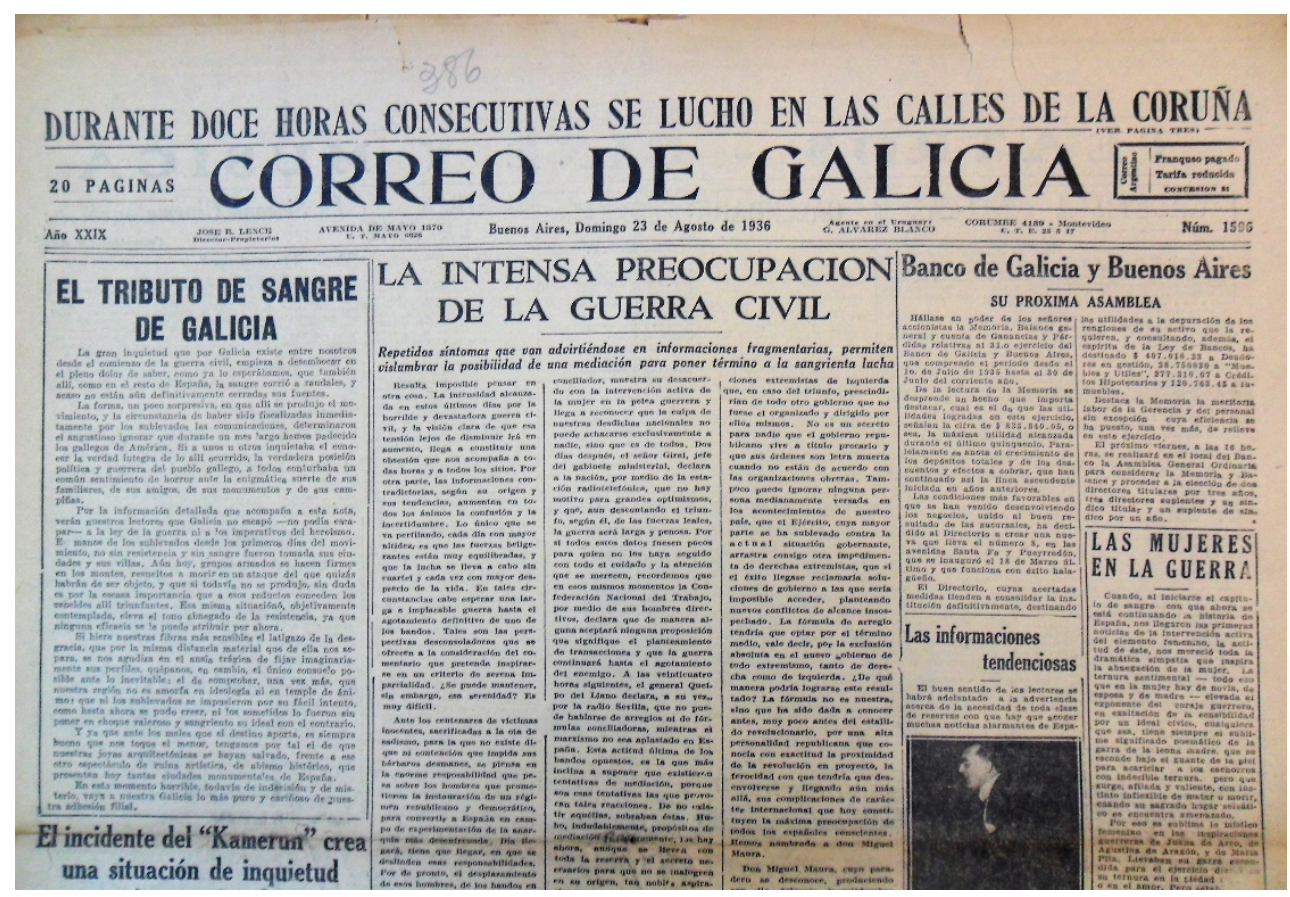

Imagen 1: La centralidad de la Guerra Civil en Correo de Galicia.

Fuente: Correo de Galicia (23 de agosto de 1936), año XXIX, no 1596, portada.

En segundo lugar, Lence trataba de extender su mensaje a la vecina orilla uruguaya, que también se había convertido en un espacio de disputa de los bandos contendientes en la península. Recordemos que en Montevideo la comunidad española era antigua y numerosa, y la Guerra Civil dividió opiniones, forjando alianzas y oposiciones dentro de la misma (Zubillaga, 2009: 46-48). Con el fin de ampliar su radio de acción, Lence puso a disposición de su mensaje pro franquista a la citada sección "Semana Española del Uruguay", la que contenía detalladas noticias sobre las actividades de propaganda de los nacionales en dicho país y relatos tendenciosos de los principales sucesos de la contienda española, destinados al público lector uruguayo. 


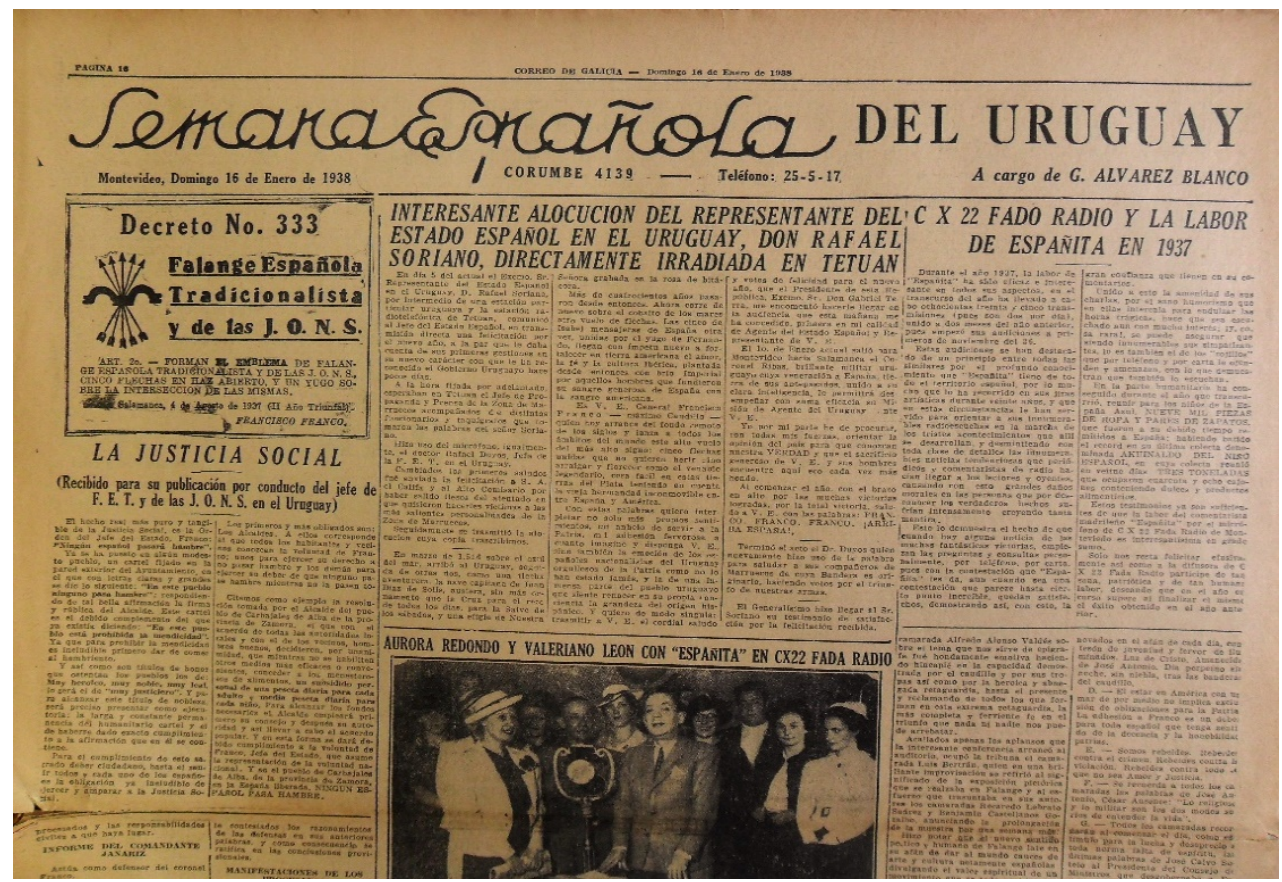

Imagen 2: La sección "Semana Española del Uruguay" en Correo de Galicia.

Fuente: Correo de Galicia (16 de enero de 1938), año XXX, no 1669, p. 16.

En tercer lugar, desde los últimos meses de 1936 y durante los años subsiguientes de la Guerra Civil, el Correo de Galicia reflejó las decisiones y acciones de la Representación del Gobierno del General Franco en Buenos Aires, desde aquellas que tenían que ver con la evolución propiamente política de esa Representación, que culminó con la llegada de Juan Pablo de Lojendio a la Embajada y Consulado de España en la capital argentina para asumir funciones como Encargado de Negocios de España, ${ }^{6}$ hasta otras quizás menos trascendentales a nivel de política pública, pero de importancia para la vida cotidiana de los emigrados, como era la organización de mecanismos para el envío de ropas de abrigo a familiares y/o peninsulares que habían residido en la Argentina y que se encontraban en el territorio dominado por los nacionales. ${ }^{7}$ Además de las colaboraciones materiales, Correo de Galicia también se hizo eco de una campaña lanzada en 1938, a través de la cual se invitaba a los emigrados a comprar una "caja bicolor" con un "valioso obsequio emotivo" (cinco kilos de productos argentinos), que costaba unos $\$ 10$ y con cuya recaudación probablemente se contribuía a sufragar gastos de las fuerzas sublevadas. ${ }^{8}$

Pero a la par que el semanario daba a conocer las políticas de los representantes de Franco en Buenos Aires, difundía las noticias relacionadas con el devenir de los

\footnotetext{
6 "Nuestra bandera”, Correo de Galicia, 5 de marzo de 1939, año XXXI, no 1728, p. 1.

7 “Españoles: amigos de España”, Correo de Galicia, 9 de enero de 1938, año XXX, no 1668, p. 13.

${ }^{8}$ Para un ejemplo de este tipo de anuncio, cfr. Correo de Galicia, 16 de enero de 1938, año XXX, no 1669, p. 3.
} 
acontecimientos bélicos en España, ensalzando el heroísmo y las victorias del Ejército Nacional, y las políticas adoptadas por el Gobierno de Burgos, incluyendo decretos de carácter secundario, como aquel que prescribía las características que debía tener el emblema de Falange Española Tradicionalista y de las J.O.N.S. ${ }^{9}$ Las iniciativas de la Falange en la Argentina encontraban eco en el Correo de Galicia, así como las actividades propagandísticas del Gobierno de Burgos en América: las Misiones Culturales Españolas, las conferencias de destacadas personalidades afines al bando nacional, los mitines, las comidas de plato único, entre muchas otras. Para 1938 Correo de Galicia funcionaba como un órgano propagandístico oficial de los Representantes del Gobierno de Burgos en Buenos Aires, hasta tal punto que en sus páginas se daban a conocer los decretos y órdenes del Boletín Oficial del Estado Español, ${ }^{10}$ o se publicaba periódicamente un aviso que prescribía cuáles eran los medios de prensa españoles que se debían leer en el Río de la Plata (La Ametralladora, El Heraldo de Aragón, Arriba España, Libertad, Hierro, El Pueblo Gallego, Nueva Economía Nacional, $A B C$ de Sevilla), todos ellos afines al bando nacional y localizables en Buenos Aires a través de la Central de Publicaciones Hispánicas. ${ }^{11}$ Es interesante señalar que, pese a los conflictos surgidos en las relaciones entre la Representación del Gobierno Nacionalista en Buenos Aires, encarnada en la figura de Juan Pablo de Lojendio, y la Falange Española en dicha ciudad (Pardo Sanz, 1992: 222-223), la imagen de las vinculaciones entre ambas instituciones en las páginas del semanario resultaba armónica: se buscaba dar una idea de unidad y de acción mancomunada entre las distintas fuerzas pro franquistas, borrándose los síntomas de las controversias existentes entre las mismas.

No obstante ello, Lence fue gestando una actitud crítica hacia el accionar de Juan Pablo de Lojendio en Buenos Aires, atribuyéndole un comportamiento elitista, limitado a un pequeño círculo de españoles acaudalados y alejado de la necesidad de convencer a las masas migrantes sobre la legitimidad del combate abierto por los sublevados (Cava Mesa, 2013: 254-255; Ferreyra, 2016: 128-129). Pero si por un lado el apoyo brindado por Lence al Representante del Gobierno de Burgos en la Argentina se fue limitando progresivamente, y ello sería reflejado en el Correo de Galicia (Ferreyra, 2016: 133), ${ }^{12}$ por otro lado, el director de este último semanario fue manifestando un beneplácito creciente con la Falange española en la Argentina. Lence mostraba con ello una actitud oportunista, que iba de la mano de la mayor injerencia que el mismo Franco buscaba dar a la Falange en América, como vía para unificar y centralizar las actividades propagandísticas y de recaudación a favor del bando nacional. Para 1938 la relación

\footnotetext{
9 “Decreto No. 333”, Correo de Galicia, 9 de enero de 1938, año XXX, no 1668, p. 16.

${ }^{10}$ Cfr., por ejemplo: "Boletín Oficial del Estado Español”, Correo de Galicia, 30 de enero de 1938, Año XXX, no 1671 , p. 2.

${ }^{11}$ Cfr. como ejemplo: Correo de Galicia, 23 de enero de 1938, año XXX, no 1670, p. 2.

12 “Don Juan Pablo de Logendio (sic)”, Correo de Galicia, 27 de febrero de 1938, año XXX, no 1675, p. 1.
} 
entre Correo de Galicia y Falange española en la Argentina era muy cordial y próxima, hasta tal punto que en su № 1670, del 23 de enero de 1938, el semanario reprodujo en su portada, y de puño y letra, la nota que el inspector general de Falange Española en América, Augusto Atalaya, hizo llegar al periódico dirigido por Lence, durante su estadía en Buenos Aires, donde daba cuenta del respeto que le prodigaba a Correo de Galicia, y cómo lo utilizaba como vía de comunicación con los emigrados afines al bando nacional. ${ }^{13}$

Continuando con el comentario de las estrategias desplegadas por el semanario para fortalecer el apoyo al bando nacional, podríamos indicar que, en cuarto lugar, en sus páginas se reflejaba la visión de la historia y del futuro que el franquismo buscaba proyectar desde la península. Un pasado que se articulaba con la etapa imperial y un futuro que, en línea de continuidad con esa experiencia de dominación y consolidación política, se encaminaría a su revitalización, dado que supuestamente sus bases y principios se encontraban en estado latente. El resurgimiento de ese imperio en América se lograría gracias a la acción de la cruz y no de las armas, es decir, se preveía una expansión espiritual que generaría una nueva época de grandeza para España, conformada por un "pueblo fuerte" que merecía dicho destino. ${ }^{14}$ Por esta vía, las naciones americanas se incorporarían de manera necesaria en esa Nueva España, la cual debía controlar además el Mar Mediterráneo para garantizar su reproducción material. $^{15}$

En quinto lugar, Correo de Galicia daba a conocer con gran detalle todas las iniciativas de las entidades afines al bando nacional, tanto de aquellas representativas de la comunidad gallega instalada en Buenos Aires (especialmente, el Patronato Gallego de Santiago Apóstol, la Acción Gallega de Cruzados de Santiago o el Ropero de Santiago Apóstol), como de algunas españolas en general (el Club Español, el Centro Acción Española o la Falange Española Tradicionalista y de las J.O.N.S.). En sus páginas se hacía hincapié en las actividades organizadas por dichas instituciones (principalmente, de las gallegas), haciendo hincapié en aquellas que contribuían a la consolidación del bando nacional, ya sea a nivel material o ideológico. Un ejemplo de ello, entre muchos otros, lo tenemos en la noticia aparecida el 6 de febrero de 1938, que anunciaba que el Patronato Gallego de Santiago Apóstol había decidido recolectar y girar a la España Nacionalista una suma de dinero para que se restauraran los templos incendiados por

\footnotetext{
13 “El Generalísimo en la intimidad", Correo de Galicia, 23 de enero de 1938, año XXX, no 1670, p. 1.

${ }^{14}$ CAPÚA, M.C. de (22 de enero de 1939): "España Imperial”, Correo de Galicia, año XXXI, no 1722, p. 5; HUARTE, J. (9 de enero de 1938): “Política imperial”, Correo de Galicia, año XXX, no 1668, p. 16.

15 "La política Hispanoamericanista del gobierno de Burgos", Correo de Galicia, 8 de enero de 1939, año XXXI, no 1720, p. 1; “España como potencia europea”, Correo de Galicia, 8 de enero de 1939, año XXXI, no 1720, p. 1.
} 
el Ejército Republicano. ${ }^{16}$ También tengamos presente que en la Sección "Movimiento colectivo-Centros y Sociedades" de Correo de Galicia se difundían las novedades institucionales (designación de nuevas autoridades, convocatoria de asambleas generales, fiestas campestres y otros actos recreativos y culturales) de aquellas entidades gallegas comprometidas en mayor o menor grado con el bando nacional, excluyéndose de esta posibilidad a aquellas que eran partidarias del gobierno republicano.

Correo de Galicia llegó incluso a arrogarse la potestad de inmiscuirse en el desenvolvimiento interno de la entidad más importante representativa del colectivo asturiano en la ciudad porteña: el Centro Asturiano de Buenos Aires, argumentando que su directiva se mantenía afín al bando republicano. En marzo de 1939, cuando ya era inminente el triunfo definitivo de Franco, el semanario alegaba que la directiva de dicha entidad ya no podía seguir defendiendo dicha postura. Correo de Galicia instaba a la Agrupación Covadonga (de inclinación nacionalista) a que exigiera a la Comisión Directiva del Centro Asturiano su renuncia, con el fin de que pudiera flamear en dicha institución la bandera roja y gualda y se lograran imponer en su seno los ideales nacionalistas. ${ }^{17}$

\subsection{Fe Gallega: el portavoz de la Cruzada católica en el Río de la Plata}

Los propósitos iniciales de Fe Gallega se relacionaron con los intentos de estimular y difundir prácticas benéficas y culturales entre los emigrados gallegos, pero en clave cristiana, con el objetivo principal de "recristianizar" a la comunidad del noroeste hispánico instalada en la ciudad de Buenos Aires y sus alrededores, bajo el supuesto de que esta última había perdido sus convicciones religiosas. ${ }^{18}$ Pero como órgano de la Acción Gallega de Cruzados de Santiago, Fe Gallega nació con una clara y fuerte vocación pro franquista que, como veremos, se postuló y se trató de implantar entre sus lectores desde el comienzo de su publicación. ¿Cuáles fueron entonces los mecanismos a través de los cuales el periódico en cuestión favoreció este activismo a favor de los sublevados?

Para empezar, Fe Gallega, lejos de posibles cavilaciones, bregó desde su primer número por una definición abierta a favor del levantamiento y del bando nacional. El periódico

\footnotetext{
16 "Patronato Gallego de Santiago Apóstol”, Correo de Galicia, 6 de febrero de 1938, año XXX, no 1672, p. 2.

17 "El triunfo de España y el Centro Asturiano", Correo de Galicia, 5 de marzo de 1939, año XXXI, no 1728, p. 3; TORVISO, P. (12 de marzo de 1939): "Un deber de la Agrupación Covadonga ante la colectividad asturiana", Correo de Galicia, año XXXI, no 1729, p. 3.

18 "En marcha”, Fe Gallega, 1ㅇ de noviembre de 1936, año I, no 1, p. 1.
} 
sostenía que había llegado la hora de abandonar las "consciencias híbridas" (aludiendo con el ello al "neutralismo" que orientaba a muchas instituciones gallegas y españolas en general), para "dar la cara", "ser algo" y "definirse". ${ }^{19}$ La justificación para adoptar esta actitud descansaba en el hecho de que, según Fe Gallega, la religión católica no toleraba la neutralidad y había que apoyar al partido político comprometido en la defensa del catolicismo. ${ }^{20}$

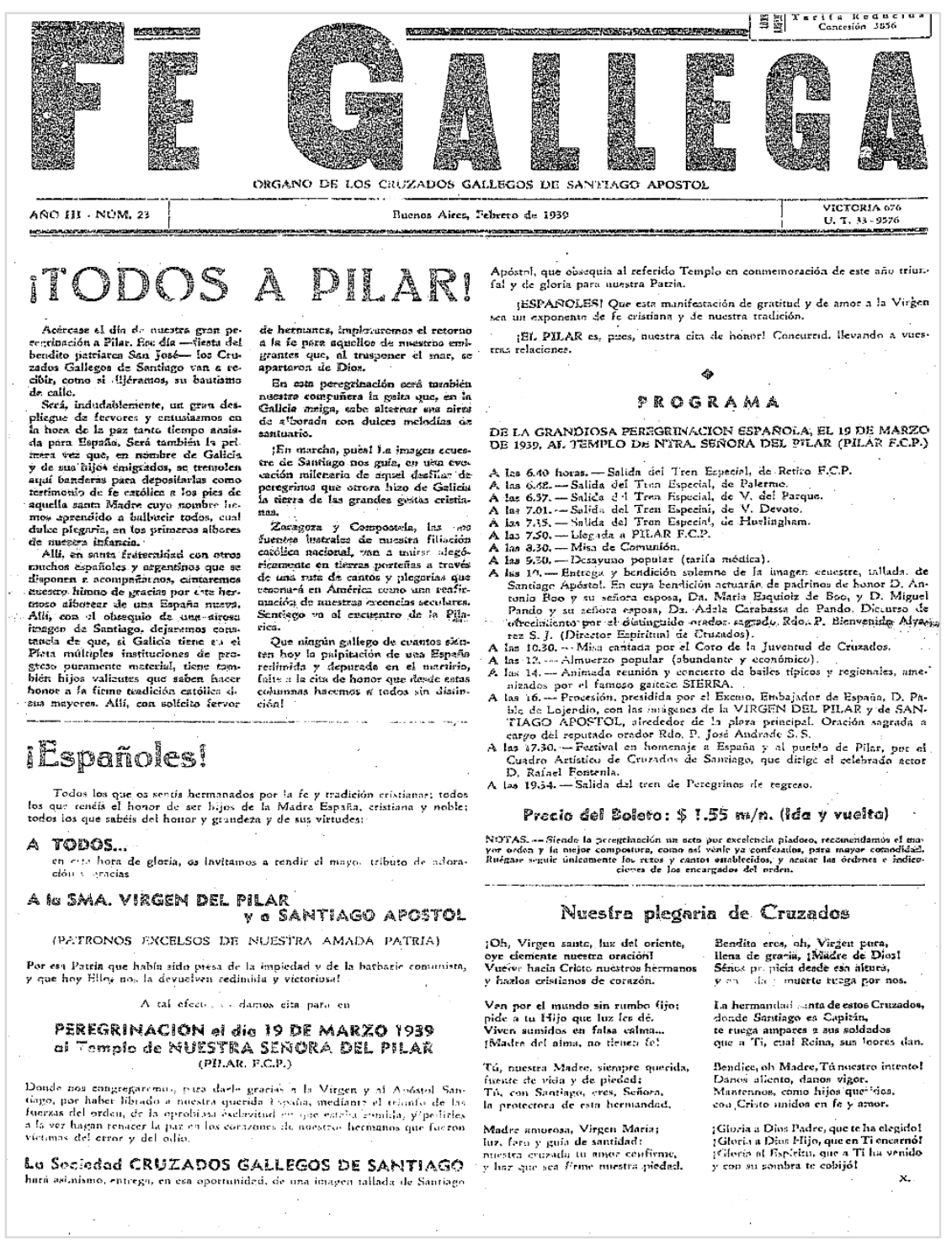

Imagen 3: Anuncio de la peregrinación al templo de Nuestra Señora del Pilar en Fe Gallega.

Fuente: Fe Gallega (febrero de 1939), año III, № 23, portada.

En segundo lugar, Fe Gallega recreó la imagen del enemigo que el bando nacional trató de afianzar en España desde el mismo momento de la sublevación: aquel encarnado en el "comunismo judaico" y en la "anarquía" (y posteriormente, también en la

\footnotetext{
19 "Sí o no", Fe Gallega, 10 de noviembre de 1936, año I, no 1, p. 1.

20 “¿Y en política?”, Fe Gallega, 1을 de noviembre de 1936, año I, no 1, p. 2.
} 
"masonería"), lo cual justificaba la reacción a favor de una España caracterizada por valores que se concebían como genuinos, arraigados e inmanentes en todo español: el "temple cristiano", las "heroicas virtudes raciales", la patria o el hogar, principalmente. ${ }^{21}$ El leitmotiv de Fe Gallega descansaba en la idea de la necesidad de la defensa de la nación frente a un invasor extranjero que propiciaría la disgregación interior, imagen que se buscó consolidar en la España insurgente desde los primeros días del levantamiento (Núñez Seixas, 2006: 180-189). La empresa de "limpieza" de un enemigo externo se complementaría con la "purga" del enemigo interno, ${ }^{22}$ lo que presuponía una visión orgánica de la nación y una asociación del enemigo con lo impuro, innecesario y negativo para dicho organismo. Además, esa lucha contra el enemigo se presentaba como una "Cruzada", como un "combate universal entre las fuerzas cristianas y las herejías anticatólicas", idea en la que abrevaba el discurso nacionalista de la guerra en numerosísimos medios de expresión y propaganda, tanto españoles como en las sociedades de emigración de los peninsulares (Pizarroso Quintero y Sapag Muñoz de la Peña, 2012: 25).

En tercer lugar, en Fe Gallega se apelaba a promover el regionalismo galaico, a ensalzar a Galicia, sus hombres y sus logros, como vía para afianzar al nacionalismo español propugnado por el bando sublevado. La reivindicación de la "identidad gallega" se llevaba a cabo por medio de distintas estrategias: la creación de un himno institucional que ponía en el centro del mensaje a la región gallega y al apóstol Santiago el Mayor; ${ }^{23}$ el uso (aunque limitado) del gallego en algunos artículos de opinión breves o en poesías que remitían a fortalecer los vínculos sentimentales de los lectores con la tierra de nacimiento; ${ }^{24}$ la alusión al origen gallego de Franco, al accionar exitoso de las fuerzas sublevadas en Galicia y a la participación de los oriundos del noroeste hispánico dentro de Ejército Nacional; ${ }^{25}$ o la defensa de la moción para incluir la cruz de Santiago en el escudo de España, ${ }^{26}$ entre otras. Pero esta cultura subestatal no era opuesta ni excluía al nacionalismo español que se buscaba reafirmar. Por el contrario, se suponía que la defensa de la primera podía contribuir a la consolidación del segundo, como sugerimos. De allí que en Fe Gallega se sostuviera que "la patria chica debe vivir siempre dentro de

\footnotetext{
21 "España decide", Fe Gallega, 1 o de noviembre de 1936, año I, no 1, p. 2; "Los vivillos de ahora”, Fe Gallega, 1 ㅇ de noviembre de 1936, año I, no 1, p. 4; "España, tierra de mártires", Fe Gallega, diciembre de 1936, año I, no 2, p. 1.

22 “iEspañoles!”, Fe Gallega, 1ำ de noviembre de 1936, año I, no 1, p. 4.

23 “Cruzados de Santiago”, Fe Gallega, diciembre de 1936, año I, no 2, p. 2.

24 TRIGAS, L. (10 de noviembre de 1936): “Galicia presente”, Fe Gallega, año I, no 1, p. 3; RODRíGUEZ DÍAZ, R. (diciembre de 1936): "Saludo d’hirmans", Fe Gallega, año I, no 2, p. 2.

25 “Redentores de pacotilla”, Fe Gallega, marzo de 1938, año II, no 15, p. 1.

${ }^{26}$ GARCíA SANCHIZ, F. (julio de 1937): “La Cruz de Santiago en el escudo de España”, Fe Gallega, año I, no 9 , p. 2.
} 
la patria grande", o se esgrimiera el postulado de la existencia y necesidad de una "España como hogar único", más allá de los regionalismos. ${ }^{27}$

En cuarto lugar, Fe Gallega difundía con elogios y detalle todas las actividades que llevaba a cabo la Acción Gallega de Cruzados de Santiago, o sus miembros más destacados, a favor de la causa nacional. Se trataba de un variado conjunto de iniciativas: en primer término, las misas que se acompañaban de diversos gestos a favor de Franco, como aquella que la citada entidad realizó junto a la Sociedad Española de la Virgen del Pilar en la Iglesia parroquial de San Isidro, en la cual se veneró la reliquia del santo como "acto de desagravio por las profanaciones del comunismo en España" y para “impetrar de Dios el triunfo del ejército salvador". ${ }^{28}$ En segundo término, los festivales. Estos últimos, organizados principalmente por la Comisión de Damas y/o la Sección Artística de la Acción Gallega de Cruzados de Santiago, tenían lugar en su sede institucional o en otros espacios culturales (como el Teatro Avenida, el Teatro Ateneo o la Biblioteca del Consejo de Mujeres de la ciudad de Buenos Aires) e incluían variados números artísticos: charlas, cantos, bailes, pasos de comedias o recitaciones de poesías, predominantemente vinculados a temáticas gallegas o interpretados por peninsulares del noroeste hispánico, aunque sin que quedaran soslayados los números que venían a encarnar el espíritu nacional defendido por los sublevados, como los pasodobles. ${ }^{29}$ En algunos de estos festivales se llegó a recolectar dinero que era enviado a España, a beneficio de la causa nacionalista. ${ }^{30}$ En tercer término, las emisiones radiales, como aquellas que tenían lugar en Radio Ultra y que podían consistir, por ejemplo, en un homenaje al natalicio de Francisco Franco durante el cual un reconocido artista gallego, Rafael Fontenla, recitó una poesía compuesta para la ocasión por el Director de $\mathrm{Fe}$ Gallega, Rogelio Rodríguez Díaz, ${ }^{31}$ quien también se desempeñaba como Secretario de la Junta Ejecutiva de Caballeros de la Acción Gallega de Cruzados de Santiago. En cuarto término, la creación de una organización, los Legionarios Civiles de Franco, compuesta por un núcleo de jóvenes de la institución en consideración, preparados especialmente para difundir en la prensa y en la calle la "obra de apostolado" de la misma. ${ }^{32}$ En quinto término, y aunque no fue un rasgo definitorio de la entidad en cuestión, algunas colectas y donaciones para el Ejército Nacional, que se vehiculaban a través del Ropero de

\footnotetext{
27 LAJE GARCíA, L. (febrero de 1939): “Más franquistas que Franco", Fe Gallega, año III, no 23, p. 3. "Todos unos", Fe Gallega, julio de 1938, año II, no 18, p. 1.

28 “El perdón de nuestros Cruzados”, Fe Gallega, enero de 1937, año I, no 3, p. 3.

29 “El primer festival de Acción Gallega de Cruzados de Santiago", Fe Gallega, 1o de noviembre de 1936, año I, no 1, p. 3; "Resultado de nuestro gran festival en el Avenida”, Fe Gallega, agosto de 1937, año I, no 10, p. 2.

30 "Nuestro aporte a la causa", Fe Gallega, diciembre de 1938, año II, no 20, p. 2.

31 “Saludo a Franco", Fe Gallega, diciembre de 1936, año I, no 2, p. 2.

32 “Legionarios de Santiago", Fe Gallega, diciembre de 1936, año I, no 2, p. 2.
} 
Santiago Apóstol. ${ }^{33}$ Vale la pena destacar que la obra de proselitismo católico y a favor del bando nacional que se proponía llevar a cabo la Acción Gallega de Cruzados de Santiago se complementaba con otra tendiente al socorro y asistencia del necesitado (otorgamiento de limosnas o donativos, provisión de empleos, ayuda en la solución de trámites complejos, visita de enfermos y encarcelados, etc.), ${ }^{34}$ en coincidencia con los fines filantrópicos y asistenciales que caracterizaron a muchas otras entidades gallegas en la Argentina, desde fines del siglo XIX.

En quinto lugar, Fe Gallega buscó ampliar su radio de acción e influencia más allá de la ciudad de Buenos Aires y sus alrededores. Con orgullo y felicidad se anunciaba en su № 3 de enero de 1937 que la publicación ya tenía varios suscriptores en Rosario y hasta un "entusiasta colaborador" en dicha ciudad. ${ }^{35}$ Se esperaba que todos ellos se sumaran a la "campaña galleguista y humanitaria" que estaban llevando a cabo desde la Capital Federal.

En sexto lugar, Fe Gallega publicaba cartas y notas de importantes figuras de las fuerzas nacionales, quienes recibían noticias de la existencia y los propósitos de la Acción Gallega de Cruzados de Santiago y manifestaban su beneplácito con la misma. Una de esas misivas fue la del secretario de Franco, quien escribiendo en su nombre, puso de manifiesto el hondo agrado que le producía al General tomar conocimiento de la campaña que desplegaba la institución gallega desde Buenos Aires, a favor del Movimiento Nacional Español. ${ }^{36}$

En séptimo lugar, el órgano de la Acción Gallega de Cruzados de Santiago difundía los listados de libros cuya lectura recomendaba enfáticamente, todos ellos con una fuerte impronta pro franquista. Este tipo de anuncio señalaba también dónde se podían conseguir las obras (en la Librería del Colegio, en Capital Federal). ${ }^{37}$

En octavo lugar, Fe Gallega dio a conocer las acciones formales de los encargados de llevar a cabo la propaganda del bando nacional en el Río de la Plata: por un lado, aquellos que pertenecían a la Representación del gobierno de Burgos en Buenos Aires y por otro, los integrantes de la Falange Española Tradicionalista y de las J.O.N.S. Pero el periódico no solo reflejó sus actividades, sino que también puso en evidencia cómo la Falange fue

\footnotetext{
33 “Donativos", Fe Gallega, mayo de 1937, año I, no 7, p. 4.

34 “Acción Gallega de Cruzados de Santiago. Carta Orgánica”, Fe Gallega. Órgano de la Acción Gallega de Cruzados de Santiago (en adelante: Fe Gallega), diciembre de 1936, año I, no 2, p. 3.

35 “Nuestros Cruzados en Rosario", Fe Gallega, enero de 1937, año I, no 3, p. 2.

36 “Una carta de Franco, que nos honra”, Fe Gallega, febrero de 1937, año I, no 4, p. 1.

37 “Libros profundamente interesantes para conocer la génesis, desarrollo y episodios del alzamiento nacional y la guerra civil española", Fe Gallega, enero de 1937, año I, no 3, p. 3.
} 
adquiriendo una influencia creciente, sobre el desenvolvimiento institucional de la Acción Gallega de Cruzados de Santiago.

Por una parte, en una primera etapa Fe Gallega reivindicó las ideas y acciones de Juan Pablo de Lojendio y José Ignacio Ramos en la capital porteña, como la visita oficial del primero (el 16 de enero de 1937) a las instituciones agrupadas en el Centro Acción Española, entre las que se encontraba la Acción Gallega de Cruzados de Santiago. ${ }^{38} \mathrm{El}$ periódico también publicaba una entrevista personal al Delegado de Prensa y Propaganda en Buenos Aires, argumentando que era un deber y honor contar con sus palabras. $^{39}$

Pero por otra parte, Fe Gallega fue poniendo de manifiesto la creciente injerencia de los falangistas sobre la Acción Gallega de Cruzados de Santiago. De este modo, cuando esta última se trasladó de su antiguo domicilio en la sede del Centro Acción Española (en Bernardo de Irigoyen 483) a la calle Victoria 676 de la ciudad de Buenos Aires, los falangistas fueron los primeros en visitar el nuevo local institucional, uniéndose a los miembros de la Acción Gallega de Cruzados de Santiago en un brindis improvisado. Desde ese momento, la última entidad prometió recibirlos en todo momento en su recién estrenada sede social, como si fuera su propio hogar. ${ }^{40}$ Los vínculos con los falangistas se afianzaron aún más cuando la entonces denominada Cruzados Gallegos de Santiago Apóstol realizó un homenaje a los primeros y les obsequió una estatua del Corazón de Jesús, que fue entronizada en su sede social. ${ }^{41}$ Como afirmó Velasco Martínez (2018: 394), los actos con los falangistas se convirtieron en parte de una dinámica habitual y hasta los Legionarios de Santiago pasaron a ser un grupo de apoyo directo de ellos.

\section{Conclusiones}

Tanto Correo de Galicia como Fe Gallega manifestaron su abierto apoyo al franquismo en la ciudad de Buenos Aires, pero con ciertas diferencias que resulta de interés tener presente. Por un lado, el órgano de difusión de la Acción Gallega de Cruzados de Santiago se apoyó en su prédica cristianizadora e identificó su tarea proselitista a favor del bando nacional en términos de "Cruzada" contra un enemigo definido desde el inicio de la contienda: principalmente, aunque no únicamente, aquel denominado como

\footnotetext{
38 “Visita del Representante de Franco", Fe Gallega, julio de 1937, año I, no 9, p. 3.

39 “Don José Ignacio Ramos habla para Fe Gallega”, Fe Gallega, abril de 1937, año I, no 6, p. 2.

40 “¡Bravo por los Falangistas!”, Fe Gallega, enero de 1938, año II, no 14, p. 3.

41 “Homenajes”, Fe Gallega, agosto de 1938, año II, no 19, p. 2.
} 
"comunismo judaico". Esta defensa de la religión católica como principio supremo estuvo ausente en Correo de Galicia, el cual mantuvo su tónica laica, desprovista de toda connotación religiosa, a lo largo de toda la contienda y tras el fin de la misma.

Por otro lado, Fe Gallega apeló abiertamente a la identificación de sus lectores con Galicia como vía para fortalecer un sentimiento de pertenencia nacional dentro del cual, de cierta forma, tenían cabida las expresiones regionales españolas, especialmente aquellas que, como la gallega, había contribuido supuestamente desde un comienzo con el progresivo afianzamiento del bando nacional. La identidad gallega se hacía visible a lo largo de todos los números del mencionado periódico, ya sea a través de sus expresiones culturales, o de los hombres y mujeres hacedores de las mismas. Esta reivindicación de un regionalismo cultural se encontraba bastante desdibujado, cuando no directamente ausente, en Correo de Galicia, en los años de la Guerra Civil española. Si bien en este semanario se tendía a poner énfasis en el accionar de las instituciones pro franquistas gallegas, en su vida societaria y en sus acciones a favor del Ejército Nacional, no se buscaba con ello la exaltación de una identificación regional, sino más bien informar o poner de manifiesto de modo secuencial las labores concretas de dichas entidades, de cara a fortalecer la retaguardia franquista en el Río de la Plata.

Finalmente, en las páginas de Fe Gallega se hallaba presente la figura del emigrado del noroeste hispánico, sus preocupaciones y necesidades. Distintas notas y comentarios daban cuenta de una sensibilidad por las cuestiones que aquejaban a los que se habían trasladado a la América austral (la falta de empleo, las enfermedades, la carencia de liderazgos positivos, la pérdida del sentido comunitario y de las creencias religiosas, entre otras), con el fin de mitigarlas. El órgano de la Acción Gallega de Cruzados de Santiago se asemejaba en ello a los periódicos de las asociaciones étnicas, atentos a dispensar servicios y prestaciones de distinto tipo a la masa de afiliados.

Pero más allá de estas diferencias, que no se agotan completamente en las aquí destacadas, Fe Gallega y Correo de Galicia compartieron un rasgo central: el hecho de erigirse en órganos propagandísticos del bando nacional en la América del Sur, como ya explicamos. El primero de manera explícita desde su número inicial, y el segundo, de forma un tanto ambigua en las primeras semanas de la Guerra Civil, pero de modo abierto a partir de septiembre de 1936. Ambas publicaciones intentaron ir más allá de la ciudad de Buenos Aires en su radio de influencia y también reflejaron los principales acontecimientos de la Guerra Civil española de forma tergiversada, describiendo las acciones bélicas en beneficio del Ejército Nacional y con el propósito de exaltar sus logros y avances en los frentes de combate. Tanto Fe Gallega como Correo de Galicia recuperaron además los principios ideológicos que formulaba el franquismo en la península y los difundieron con el objeto de que se encarnasen en el público lector y más allá del mismo. 
Ahora bien, ¿cuáles fueron los alcances de esta prédica? ¿Hasta qué punto estas publicaciones lograron convencer a sus lectores de la legitimidad y de los beneficios del accionar del bando nacional en la península? Resulta difícil responder a estas preguntas a partir de las fuentes disponibles. En el caso de Correo de Galicia, su director advirtió que la definición del semanario a favor del franquismo, antes que propiciar un aumento de su público lector entre la comunidad española, lo terminó disminuyendo (Lence, 1954: 341). La mayor parte del colectivo español estuvo en contra, resistió o permaneció neutral ante la prédica a favor del bando nacional y por el contrario, se manifestó partidaria del gobierno republicano (Quijada Mauriño, 1991: 17). Ello en cierta medida se debía a que los representantes franquistas disponían de escasos recursos financieros destinados a la propaganda en la Argentina y en el resto de los países americanos (Pardo Sanz, 1992: 225; Rein, 1995: 42). De allí que durante la Guerra Civil los efectos de la propaganda franquista en la nación austral resultaran limitados, y ello se torna más evidente si los comparamos con los alcances más amplios logrados allí por la propaganda republicana. En una entrevista concedida a Correo de Galicia a principios de $1939,{ }^{42}$ Juan Pablo de Lojendio ponía de relieve que la batalla que había librar una vez ganada la guerra era la de la propaganda, la conquista de aquellos corazones indiferentes o afines al republicanismo que aún no se habían logrado cooptar, justamente porque se consideraba que esa tarea había quedado inacabada durante la contienda. Al término de esta última, el propósito de convencer a una gran parte de la opinión pública española sobre la necesidad y legitimidad del franquismo constituía todavía un desafío y un objetivo pendiente.

\section{Referencias bibliográficas}

CAGIAO VILA, P. (2002): "Los gallegos en Buenos Aires a través de la prensa de la colectividad, 1925-1930", en Campos Álvarez, X.R. y Rey Tristán, E. (editores), Actas del III Congreso de Historiadores Latinoamericanistas (ADHILAC) [CD-ROM], Santiago de Compostela, Universidad de Vigo - Universidad de Santiago de Compostela - ADHILAC - Revista La Formación del Historiador.

CAVA MESA, M.J. (2013): “Juan Pablo de Lojendio e Irure (1906-1973). El balcón de las apariencias", en Moreno Cantano, A.C. (coordinador), Cruzados de Franco. Propaganda y diplomacia en tiempos de guerra (1936-1945), Gijón, Ediciones Trea, pp. 241-269.

\footnotetext{
42 "El nuevo año que hoy comienza marcará el triunfo definitivo de la causa nacional española”, Correo de Galicia, 1ㅇ de enero de 1939, año XXXI, no 1719, p. 1.
} 
Cuarto Censo General de la Ciudad de Buenos Aires (1936), Buenos Aires, Municipalidad de la Ciudad de Buenos Aires, T. II.

DE CRISTÓFORIS, N. (2009): Proa al Plata: las migraciones de gallegos y asturianos a Buenos Aires (fines del siglo XVIII y comienzos del XIX), Madrid, CSIC.

FASANO, L. (2014): Los exiliados republicanos en Buenos Aires: labor política y cultural en el ámbito de la comunidad gallega (1936-1955), Tesis doctoral, Buenos Aires, Universidad de Buenos Aires.

FARÍAS, R. (2008): "Galicia y los gallegos desde la mirada de Caras y Caretas", en Lojo, M.R. (directora), Los "gallegos" en el imaginario argentino. Literatura, sainete, prensa, Fundación Pedro Barrié de la Maza, pp. 201-269.

- (2010): La inmigración gallega en el Sur del Gran Buenos Aires, 1869-1960, Tesis doctoral, Santiago de Compostela, Universidade de Santiago de Compostela. Disponible en Internet (5-02-2019): https://minerva.usc.es/xmlui/bitstream/handle/10347/2784/9788498873559_co ntent.pdf?sequence $=1$

FERNÁNDEZ GARCÍA, A. (1990): “Los círculos de emigrantes ante la guerra de España: la colonia gallega de Buenos Aires", Quinto Centenario, no 16, pp. 121-140.

FERNÁNDEZ SANTANDER, C. (2000): El alzamiento de 1936 en Galicia, Sada-A Coruña, Ediciós do Castro.

FERNÁNDEZ SANTIAGO, M. (2001): “Asociacionismo gallego en Buenos Aires (19361960)", en Núñez Seixas, X.M. (editor), La Galicia Austral. La inmigración gallega en la Argentina, Buenos Aires, Biblos, pp. 181-201.

FERREYRA, A. (2016): "La acción propagandística a favor del Franquismo durante la Guerra Civil Española: la actuación de Juan Pablo Lojendio en Buenos Aires (19361939)" en Páginas. Revista digital de la Escuela de Historia, vol. 8, no 16, pp. 123140. Disponible en Internet (26-02-2019): http://revistapaginas.unr.edu.ar/index.php/RevPaginas/article/view/215

GARABEDIAN, M. (2017): La construcción de un colectivo español en Argentina. El Correo Español (1872-1905), Tesis doctoral, Buenos Aires, Universidad Torcuato Di Tella.

LENCE, J.R. (1954): Memorias de un periodista, Buenos Aires, Centro Difusor del Libro.

MOLINOS, R. (1999): “Medios de comunicación y prensa étnica: la experiencia urbana de los gallegos en Buenos Aires", en Gutman, M. y Reese, T. (editores), Buenos Aires 1910. El imaginario ara una gran capital, Buenos Aires, Eudeba, pp. 317-330.

MORENO CANTANO, A.C. (2008): Los servicios de prensa extranjera en el primer franquismo (1936-1945), Tesis doctoral, Alcalá de Henares, Universidad de Alcalá 
de Henares. Disponible en Internet (9-02-2019): https://dialnet.unirioja.es/descarga/tesis/24073.pdf

MOYA, J.C. (2004): Primos y extranjeros. La inmigración española en Buenos Aires, 18501930, Buenos Aires, Emecé.

NEIRA VILAS, X. (1985): A prensa galega en Cuba, Sada-A Coruña, Ediciós do Castro.

NÚÑEZ SEIXAS, X.M. (ed.) (2001): La Galicia Austral. La inmigración gallega en la Argentina, Buenos Aires, Biblos.

- (2002), O inmigrante imaxinario: Estereotipos, representacións e identidades dos galegos na Arxentina (1880-1940), Santiago de Compostela, Universidade de Santiago de Compostela.

- (2006): ¡Fuera el invasor! Nacionalismos y movilización bélica durante la guerra civil española (1936-1939), Madrid, Marcial Pons.

- (2007): “Un panorama social de la inmigración gallega en Buenos Aires, 17501930", en Farías, R. (compilador), Buenos Aires Gallega. Inmigración, pasado y presente, Buenos Aires, Comisión para la Preservación del Patrimonio Histórico Cultural de la Ciudad de Buenos Aires, pp. 45-62.

- (2012): "Política de los exiliados y política de los emigrados", en Devoto, F. y Villares, R. (editores), Luis Seoane, entre Galicia y la Argentina, Buenos Aires, Biblos, pp. 133-164.

- (2014): "Periodismo, patriotismo "regional" y estrategias de liderazgo: Fortunato Cruces, José R. Lence y los gallegos de Buenos Aires (1900-1936)", en Núñez Seixas, X.M., Las patrias ausentes. Estudios sobre historia y memoria de las migraciones ibéricas (1830-1960), Oviedo, Genueve Ediciones, pp. 413-451.

PARDO SANZ, R.M. (1992): “Hispanoamérica en la política nacionalista, 1936-1939" en Espacio, Tiempo y Forma, Serie V, Historia Contemporánea, no 5, pp. 211-238. Disponible en Internet (22-02-2019): http://revistas.uned.es/index.php/ETFV/article/view/2751

PIZARROSO QUINTERO, A. y SAPAG MUÑOZ DE LA PEÑA, P. (2012): “Propaganda y diplomacia. Proyección exterior de la España franquista (1936-1945)", en Moreno Cantano, A.C. (coordinador), Propagandistas y diplomáticos al servicio de Franco (1936-1945), Gijón, Ediciones Trea, pp. 21-54.

QUIJADA MAURIÑO, M. (1991): Aires de República, Aires de Cruzada: la Guerra Civil española en Argentina, Barcelona, Sendai Ediciones.

REIN, R. (1995): “Otro escenario de lucha: franquistas y antifranquistas en la Argentina, 1936-1949" en Ciclos, año V, vol. V, no 9, pp. 31-52. 
TRIFONE, V. y SVARZMAN, G. (1993): La repercusión de la guerra civil española en la Argentina (1936-1939), Buenos Aires, CEAL.

VELASCO MARTÍNEZ, L. (2018): “Guerra Civil y reclutamiento en la colectividad gallega en Argentina: la Acción Gallega de Caballeros de Santiago" en Cuadernos de Estudios Gallegos, vol. 65, no 131, pp. 377-401. Disponible en Internet (23-022019):

http://estudiosgallegos.revistas.csic.es/index.php/estudiosgallegos/article/view/ 444

VIEITES TORREIRO, D. (1989): "La emigración a través de la prensa gallega de Cuba y Argentina a finales del siglo XIX" en Revista da Comisión Galega do Quinto Centenario, no 6, 1990, pp. 123-133.

VILANOVA RODRÍGUEZ, A. (1966): Los gallegos en la Argentina, Buenos Aires, Ediciones Galicia, 2 Tomos.

VILLARES, R. y FERNÁNDEZ, M. (1996): Historia da emigración galega a América, Xunta de Galicia.

ZUBILLAGA BARRERA, C. (1996): A prensa galega de inmigración en Uruguai, Vigo, Consello da Cultura Galega.

- (2009): "El asociacionismo inmigratorio español en Uruguay en la mira del franquismo: entre la oposición y el disciplinamiento" en Revista de Indias, vol. XIX, no 245, pp. 43-64. Disponible en internet (10-02-2019): http://revistadeindias.revistas.csic.es/index.php/revistadeindias/article/view/66 7 